method far beyond physics was seldom matched by any comparable understanding of his scientific work, still less of its epistemological roots. Insofar as they departed from the epistemology inherent in the ways to God, they developed theories of science that would have been lethal if scientists had taken any notice of them. Fortunately they did not, so no great harm was done, at least to science itself.

The second great period of scientific creativity was initiated by Einstein and Planck, and here again the wellsprings may be traced to the same theistic source. Although initially Einstein was influenced by Mach, his scientific creativity gradually forced him to repudiate Mach's sensationalism. Its ravages are still evident in the philosophy of quantum mechanics and in Bohr's theory of complementarity.
At the present time, increasing evidence of the singularity of the Universe is again pointing to its radical contingency.

Professor Jaki develops his theme with a masterly command of the original sources, and the text is supported by over a hundred pages of notes and references. It is so densely packed with ideas that it is not easy to read, but scientists, philosophers and theologians will find it a mine of stimulating analysis. Inevitably his thesis raises many other questions such as the relationships between the Christian churches and science, which have not always been harmonious, and the acceptance of science by radically different cultures; and these are apt future subjects for Jaki's pen.

P. E. Hodgson is Lecturer in Nuclear Physics at the University of Oxford, UK.

\section{Fragmentation of culture}

\section{W. H. Brock}

Nature and the Victorian Imagination. Edited by U. C. Knoepflmacher and G. B. Tennyson. Pp. 519. (University of California Press: Berkeley, Los Angeles and London, 1978.) $£ 15$.

"WhAT a glorious title, Nature, a veritable stroke of genius to have hit upon", wrote the mathematician J. J. Sylvester enthusiastically to Nature's editor, the astronomer J. N. Lockyer, on the first appearance of the journal in November, 1869. Yet, although the title was copied by French, Italian, Dutch and Norwegian commercial science publications, it is significant that when American scientists founded a similar journal in 1883 they chose the title Science. Again, T. H. Huxley, in translating a German nature poem for the first issue of Nature, could think of no more fitting a preface for a periodical "which aims to mirror the progress of that fashioning by nature of a picture of herself, in the mind of man, which we call the progress of science". Yet, as the editors of this elegant book point out, by 1918 any serious writer, painter or scientist would have thought it "impossible, quaint, archaic, Victorian ... to rise from a bird's plumage to a consideration of man's position in the Universe".

That the scientific community pioneered this "denaturing" process few would deny. Put briefty, the collective theme of this interdisciplinary feast of a book is what S. F. Cannon has called "the fragmentation of culture", whereby the common religious, moral, poetic and scientific perspective of the early Victorians was gradually fragmented into, on the one hand, a literary consciousness which continued for a long time to seek symbols in Nature; and on the other, the various scientific forms of imagination which pursued separate, and sometimes, unrelated, disciplinary goals by measurement, experiment and abstraction. That "Ruskin ... in looking at botanical specimens... saw nothing of what Darwin saw in them", is, for example, brought out by $F$. Kirchhoff in a fascinating analysis of Ruskin's floral mythology in Proserpina.

Apart from R. Smith's fine essay on the human significance of biology, the question whether value systems were completely abandoned by scientists is, unfortunately, little explored by the 26 contributors to this volume, which is primarily addressed to the literary reader. Concentrating on the changing artistic interpretation of Nature, there are only three essays by historians of science who actually explore the directions taken by chemists, physicists and biologists during the century. These, together with a fine essay on science education from the Arnold scholar, R. H. Super, stand for the systems of knowledge that challenged traditional "inscape". Ignored, except for the editors' allusion to the nature writer, W. H. Hudson, is the powerful tradition of natural history (whose social history has been so ably analysed by D. E. Allen in The Naturalist in Britain (Allen Lane: London, 1976) which may well be seen as continuing a moralistic science long after Darwin. By the same token, the essays are exclusively concerned with the intellectuals' imagination; whereas cursory reading of "working-class" natural history journals suggests that their readers continued, like the literary

\section{PUBLIC POLICY AND THE} DIFFUSION OF TECHNOLOGY An International Comparison of Large Fossil-Fueled Generating Units

by J. DeYoung \& J. Tilton

This study investigates the adoption of new technology in the electric utility industry. It examines the rate at which the large-scale generating units have been introduced, and considers how public policy can influence this growth. Diffusion is investigated in three countries - the U.S., Canada, and Britain - focusing on the last quarter century. Penn State Univ. Press
paper 22.80

\section{ENVIRONMENTAL IMPACT \\ ANALYSIS}

\section{The Decision Process}

edited by R. K. Jain \& Bruce Hutchings

Persons in both private and public sectors, including consultants, environmental professionals, sociologists, planners, economists. and political scientists who work in environmental studies will benefit from this focused discussion of environmental impact research and its integration into the overall planning process.

Univ. of lllinois Press $208 p$. cloth $\$ 8.40$

\section{Gower Street, London W.C. 1 tel. (01) 5803994}

Circle No. 69 on Reader Enquiry Card.

and artistic intelligentsia (but unlike laboratory-bound biologists) to find mystery and feeling in Nature.

Despite such reservations the book triumphantly succeeds in revealing the many-sided character of the Victorian imagination as it responded to Nature. The essays include a photographic study of how the Victorians perceived nature through the camera lens; several interesting treatments of the ways in which natural space was tamed symbolically in architecture and domestic ornamentation; how the Victorians explored wild and mysterious environments like the Alps and subjugated them by sports and tourism; how their painters were torn between moral and realist models of representation (a notable essay here on the rainbow by G. P. Landow); and how the issues were perceived by such sages as Keble, Dickens, Browning, Mill and Hardy. Printer, publisher and editors are to be commended for placing footnotes where they belong, and for their choice of quality illustrations and fine typography. They have produced a book which is not only a pleasure to read, but also to hold, handle and shelve. $\square$

W. H. Brock is Director of the Victorian Studies Centre and Reader in the History of Science at the University of Leicester, UK. 